\title{
Is complex concomitant surgery justified or does it simply support guard rails?
}

\author{
Susan D. Moffatt-Bruce, MD, PhD, FACS, FRCSC
}

From the Division of Thoracic Surgery, Department of Surgery, The Ohio State University, Columbus, Ohio. Disclosures: Author has nothing to disclose with regard to commercial support.

Received for publication Oct 22, 2015; accepted for publication Oct 24, 2015; available ahead of print Nov 19, 2015 .

Address for reprints: Susan D. Moffatt-Bruce, MD, PhD, FACS, FRCSC, Division of Thoracic Surgery, Department of Surgery, 410 W 10th Ave, Columbus, OH 43210 (E-mail: Susan.moffatt-bruce@osumc.edu).

J Thorac Cardiovasc Surg 2016;151:568-9

0022-5223/\$36.00

Copyright (c) 2016 by The American Association for Thoracic Surgery

http://dx.doi.org/10.1016/j.jtcvs.2015.10.091

The article by Biniwale and colleagues ${ }^{1}$ truly supports the concept that we, as cardiothoracic surgeons, are embracing the value proposition that has been put before us. That is to say, adding features that give patients a greater sense of value in terms of quality outcomes in efficient settings is at the forefront of our thoughts as we traverse the choppy waters of health care reform. ${ }^{2}$

The authors ${ }^{1}$ review their outcomes of 120 patients undergoing lung transplantation and concomitant cardiac procedures, a group that represents almost $20 \%$ of the 620 lung transplantations completed during the time period (13 years) at their institution. The results reveal that when compared with a similar group of 120 lung transplant recipients who did not undergo cardiac surgery, the 5-year survival was similar. Additionally, there was no difference in the incidence of primary graft dysfunction, efficiency metrics, or major adverse events. The authors also looked at complication rates, which decrease efficiency and make cost containment difficult, and revealed that the incidences of re-exploration for bleeding, duration of invasive mechanical ventilation, need for postoperative extracorporeal membrane oxygenation, and the incidence of graft failure at 72 hours were similar between the 2 groups.

Moreover, the duration of intensive care unit and hospital stay were also similar between the 2 groups and subgroup analysis of the major concomitant surgery group did not show any difference in perioperative clinical outcomes compared with the lung transplant alone group. Finally, the authors reviewed the 5-year major adverse cardiac event rate, including atrial fibrillation (ie, documented episodes requiring treatment), episodes of acute coronary syndrome, redo revascularization or valvular procedure, episodes of congestive heart failure (requiring hospital admission), and cardiac-related deaths (including pulmonary embolism). The subgroup analysis of major adverse cardiac event rate showed no significant differences compared with the lung transplantation alone group. Clearly the argument that begins, "My patient was sicker so did not do as well" does not hold water when patients are cared for in the correct setting, by the correct caregivers.

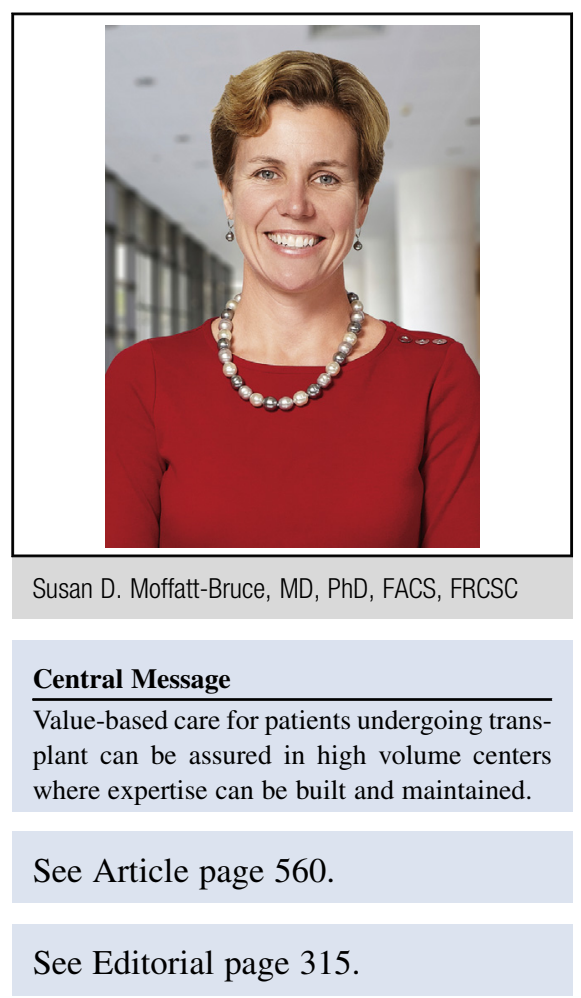

The results presented by Biniwale and colleagues ${ }^{1}$ are nothing short of outstanding. The volume of this particular program speaks to their having developed a group of care providers who are truly expert. The surgeons have gained expertise in the disease management of highly selected patients with both cardiac and thoracic conditions. As a result of working with these highly selected patients in a very high volume center, I propose that the surgeons and care providers have become highly selected as well. Well-prepared teams result in the best outcomes. ${ }^{3}$ The quality oversight that exists in transplantation requires nothing short of superb results and the Scientific Registry of Transplant Recipients infrastructure and discipline has made the reporting of this very public data actually drive improvements, in contrast to other, more passive quality assurance programs. ${ }^{4}$

Today outcomes have to be measured against cost containment - the infamous value proposition or equation. After reading the article by Biniwale and colleagues ${ }^{1}$ we have to ask whether these data support the idea of having defined centers of excellence-even super-specialized transplant centers-to which patients should be directed. It is time to regionalize high-risk and high-cost procedures and ensure outcomes similar to those presented by 
Biniwale and colleagues. ${ }^{1}$ With 73 centers performing lung transplantation procedures across the nation, and considering the generally accepted contraindications and relative contraindications to lung transplantation and the recognition of scarce organ and financial resources, should all thoracic transplant surgeons be driving outside the guard rails? I think not. There is growing need and support for providing patients with the highest level of care at the right place and by the right surgeons. ${ }^{3,5}$ Whilst only a few brave centers have made the pledge to really institutionalize the low-volume paradigm across all disciplines, the article by Biniwale and colleagues ${ }^{1}$ reminds us that at a minimum, in the world of lung transplantation, expertise is a earned privilege, not a right, and only once attained and maintained, will we allow for high-valued care for patients undergoing transplant who have increasingly complex conditions.

\section{References}

1. Biniwale R, Ross D, Iyengar A, Kwon OJ, Hunter C, Aboulhosn J, et al Lung transplantation and concomitant cardiac surgery: is it justified? J Thorac Cardiovasc Surg. 2016;151:560-7.

2. Reich DJ. Quality assessment and performance improvement in transplantation: hype or hope? Curr Opin Organ Transplant. 2013;18(2):216-21.

3. Reames BN, Ghaferi AA, Birkmeyer JD, Dimick JB. Hospital volume and operative mortality in the modern era. Ann Surg. 2014;260:244-51.

4. Osborne NH, Nicholas LH, Ryan AM, Thumma JR, Dimick JB. Association of hospital participation in a quality reporting program with surgical outcomes and expenditures for Medicare beneficiaries. JAMA. 2015;313:496-504.

5. Urbach DR. Pledging to eliminate low-volume surgery. N Engl J Med. 2015;373: 1388-90. 